\title{
Physical Chemical Properties and Kinetics of Redox Processes in Water/Soybean Oil Microemulsions
}

\author{
Carla R. B. Mendonça, ${ }^{*, a}$ Clara I. D. Bica, ${ }^{b}$ Ernesto F. Simó-Alfonso, ${ }^{c}$ Guillermo Ramis-Ramos ${ }^{c}$ \\ and Clarisse M. S. Piatnicki ${ }^{b}$
}

\author{
${ }^{a}$ Departamento de Ciência dos Alimentos, Universidade Federal de Pelotas, Campus Universitário, \\ CP 354, 96010-900 Pelotas-RS, Brazil \\ ${ }^{b}$ Instituto de Química, Universidade Federal do Rio Grande do Sul, Av. Bento Gonçalves no. 9500, \\ CP 15003, 91501-970 Porto Alegre-RS, Brazil
}

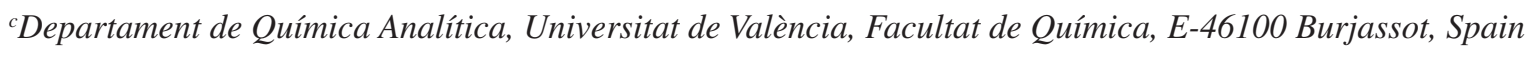

\begin{abstract}
Microemulsões de água em óleo (ME w/o) constituídas de água, óleo de soja, SDS (dodecil sulfato de sódio) e diversos álcoois de cadeia curta foram caracterizadas sob o ponto de vista físico-químico e de propriedades eletroanalíticas. Foram testados diferentes co-surfactantes e razões surfactante:cosurfactante, sendo a ME com a composição mais favorável utilizada para estudar a cinética de processos redox. Para tanto, realizaram-se medidas de voltametria cíclica utilizando como eletrodo de trabalho um ultramicroeletrodo de disco de Pt e, como eletrodo de referência e auxiliar, foram usados $\mathrm{Ag} / \mathrm{AgCl}$ e Pt, respectivamente, e ferroceno como uma sonda. Verificou-se que a estabilidade termodinâmica das MEs aumenta com o conteúdo de co-surfactante. A estrutura molecular e a solubilidade em água do co-surfactante afetam a condutividade elétrica e o raio hidrodinâmico das MEs. Devido aos baixos coeficientes de difusão observados na ME, foi possível a realização de medidas em estado transiente usando velocidades de varredura convencionais. A oxidação do ferroceno na ME demonstrou ocorrer em condições de quasi-reversibilidade. Assim, foi demonstrada a possibilidade de realizar estudos por voltametria cíclica em óleos vegetais sob a forma de ME w/o.
\end{abstract}

Water/oil microemulsions (w/o ME) constituted by water, soybean oil, SDS (sodium dodecyl sulfate) and several short-chain alcohols were characterized from the viewpoint of its physical-chemical and electroanalytical properties. Different co-surfactants and surfactant:co-surfactant ratios were used, and the ME with the most favourable composition was used to study the kinetics of redox processes. For this purpose, cyclic voltammetry measurements using a Pt disk working ultramicroelectrode, an $\mathrm{Ag} / \mathrm{AgCl}$ reference electrode and a $\mathrm{Pt}$ auxiliary electrode, and ferrocene as a probe, were performed. It was verified that the thermodynamic stability of the MEs increases with the co-surfactant content. The molecular structure and water solubility of the co-surfactant affect the electrical conductivity and the hydrodynamic radio of the MEs. Owing to the low diffusion coefficients verified in the MEs, measurements in transient state using conventional sweeping rates could be performed. Ferrocene oxidation in the ME has been demonstrated to proceed in quasi-reversibility conditions. Thus, the possibility of carrying out studies of cyclic voltammetry in vegetable oils under the w/o ME form was demonstrated.

Keywords: w/o microemulsions, physical chemical properties, redox process, cyclic voltammetry, vegetable oils

\section{Introduction}

Valuable information relative to structure evolution, inter-particle interactions and transport data of mass and charge in diverse media, can be obtained by using

\footnotetext{
*e-mail:sidcar@ufpel.edu.br
}

electrochemical techniques. ${ }^{1-3}$ However, the application of these techniques in nanoheterogeneous systems, including microemulsions (MEs), has been scarcely exploited. MEs are optically transparent, isotropic and thermodynamically stable systems. Water in oil (w/o) MEs are formed by water droplets dispersed in an oil continuous phase. These droplets, coated by monolayers of a surfactant, that may 
be intercalated by molecules of an alcohol which acts as co-surfactant..$^{4-7}$ Beyond a superior stability, these systems present good conducting properties, in general higher than those of most organic solvents, and possess a high solving power, with the added capability of simultaneously maintaining hydrophobic and hydrophilic substances in solution. ${ }^{8}$

Along the last decades, MEs have been the subject of many studies, mainly because of their potential applications in several fields, like the preparation of nanoparticles with catalytic and electrocatalytic properties, separation of water-soluble and lipid-soluble vitamins and other lipidic compounds by electrokinetic chromatography or liquid chromatography, enhanced oil recovery, liquid-liquid extraction, and removal of contaminants from solid surfaces or tissue capillaries in the pharmaceutical and cosmetic industries. ${ }^{9-11}$

Valuable electroanalytical methods for vegetable oils may be derived by preparing the samples as w/o MEs. Considering that species different from triglycerides in edible oils constitute minor components, ${ }^{12,13}$ the maximization of oil amount in a ME is desirable. On the other hand, the increase of the oil content affects expressively the electrical conductivity of these systems. It is known that oil-in-water and bi-continuous MEs have relatively high conductivities when compared to w/o ME, which are systems with a continuous organic phase. However the electrical conductivity of w/o MEs is considered high when compared to those of mixtures of non polar solvents and vegetable oils. ${ }^{14}$ In this sense, an appropriate strategy is to use a Pt disk ultramicroelectrode (UME), which provides several advantages over conventional electrodes, making feasible the study of electrode reactions in w/o MEs and other highly resistive media. ${ }^{14-17}$ The main advantages of UMEs in comparison to classic electrodes are the drastic reduction of the ohmic drop, even in the absence of an electrolyte, and the fast establishment of the steady state. These advantages are due to the small radius of UME discs, which are lower than the thickness of the diffusion layer $(\delta) .{ }^{18-21}$ In relation to a classic electrode, the faradaic-to-charging current ratio, $\mathrm{i}_{\mathrm{F}} / \mathrm{i}_{\mathrm{C}}$, is larger in an UME, which is an advantage in trace analysis. In transient regime, the $\mathrm{i}_{\mathrm{F}} / \mathrm{i}_{\mathrm{c}}$ ratio is proportional to $\mathrm{v}^{1 / 2}$, where $\mathrm{v}$ is the sweeping rate. Even in this case, an UME has the advantage of a reduced charge time, ${ }^{22,23}$ which allows the study of very fast reactions, of the order of microseconds. ${ }^{24}$ In this sense, linear voltammetry measurements ${ }^{25}$ in resistive media ${ }^{26}$ like the w/o MEs employed in this study, can be performed by an UME.
The aim of this work was to evaluate the influence of the surfactant/co-surfactant ratio on the physical-chemical characteristics of water/soybean oil w/o MEs using measurements of the hydrodynamic radius $\left(R_{H}\right)$, refractive index, viscosity and electrical conductivity, as well as to study the kinetic of redox processes by using cyclic voltammetry with an UME in the presence of ferrocene as a probe. Vegetable oil analysis is usually performed by a number of analytical techniques. However, electroanalytical techniques have been seldom employed. Application of electroanalytical methods is rapid, has a low cost, and can yield very low detection limits. Further, the possibility of directly analyzing vegetable oils, with minimal preparation of the samples, makes electroanalytical methods in w/o MEs to be particularly attractive. Possible analytical strategies to characterize the oils by electrochemical methods were discussed.

\section{Experimental}

\section{Reagents, samples and solutions}

Refined and deodorized soybean oil stored in metallic containers was obtained from the local market. To prepare the MEs, 99\% sodium dodecyl sulfate (SDS) from Merck (Darmstadt, Germany), previously distilled milli-Q water, and alternatively 99\% 1-pentanol, 99\% 3-methyl-1-butanol (Merck), or 96\% 1-hexanol (Riedel, Buchs, Switzerland), were used. Sodium tetraborate (STB) from Probus (Barcelona, Spain) was used to evaluate the stability of the MEs. Ferrocene (98\%, Fluka, Buchs, Switzerland) was employed as a probe and electrochemical reference material. ${ }^{27-29}$

Other analytical grade reagents were decaline, potassium ferricyanide, potassium perclorate, sulfuric acid and acetone (Merck).

\section{Instrumentation}

Voltammograms were obtained with an EG\&G PAR Model 264A potentiostat (Princeton Applied Research, Wellesley, MA, USA). Dynamic light scattering (DLS) measurements were performed with a spectrogoniometer (Brookhaven Instruments, Holtsville, NY, USA), provided with a 264-channel BI-9000 AT digital correlator covering seven decades in delay time (Brookhaven), and a model $170 \mathrm{He}-\mathrm{Ne}$ laser with $\lambda=632.8 \mathrm{~nm}$ from Spectra-Physics (Irvine, CA, USA). An Abbé refractometer, a Brookfield LVDV-II+ viscosimeter (Middleboro, MA, USA), and a conductimeter (microCM-2200, Crison, Barcelona, Spain), were also used. 


\section{Procedures}

\section{ME preparation and characterization}

MEs were prepared by sequentially mixing the surfactant (SDS) with an alcohol co-surfactant and water and, finally, adding soybean oil to the mixture. The proportions of the ME components were taken from a previous work, ${ }^{25}$ where the best surfactant/co-surfactant ratios, capable of producing stable thermodynamic systems, were described. However, to acquire a better knowledge about the physical-chemical properties of these MEs, different surfactant/co-surfactant ratios were also tried. The hydrodynamic radius, refractive index, viscosity and electrical conductivity were measured.

To perform DLS measurements, a refractive-indexmatching liquid (decaline) was used. In order to characterize the hydrodynamic behavior of the suspended particles, the multisampling time autocorrelation functions were analyzed by one-exponential fit (Microcal Origin 6.0) and by inverse Laplace transformation using the REPES and CONTIN programs. ${ }^{30}$ Prior to all measurements, the samples were centrifuged during $30 \mathrm{~min}$ at $4000 \mathrm{rpm}$ in order to minimize the interference of dust particles. The DLS experiments were carried out at $25.0 \pm 0.5^{\circ} \mathrm{C}$ and at a fixed scattering angle of $90^{\circ}$.

The refractive index measurements were carried out at $21.0 \pm 0.5^{\circ} \mathrm{C}$, and the viscosity and electrical conductivity experiments were performed at $25.0 \pm 0.1^{\circ} \mathrm{C}$.

\section{Influence of salt concentration on the ME stability}

Stability of MEs prepared with an alcohol as cosurfactant, and different surfactant:co-surfactant ratios, in reference to the progressive concentrations of STB within the $4 \times 10^{-2}-8 \times 10^{-2} \mathrm{~mol} \mathrm{~L}^{-1}$ range, was evaluated. Selection of STB was justified by its low cost and its capability of increasing the electrical conductivity of the medium without producing any electroanalytical signal along a wide potential range. STB is also widely employed as buffering agent in capillary electroforesis. ${ }^{31}$ Thus, STB solutions at different concentrations were used to prepare MEs. The loss of stability was evaluated by arising of cloudiness in the system.

\section{Electrochemical measurements}

Current-potential curves in MEs were obtained at $25^{\circ} \mathrm{C}$, the electrochemical cell consisting of a threeelectrode assembly with a $1 \mu \mathrm{m}$ radius $\mathrm{Pt}$ disk working $\mathrm{UME}$, a reference $\mathrm{Ag} / \mathrm{AgCl}$ electrode and an auxiliary $\mathrm{Pt}$ electrode. The Pt UME was obtained from EG\&G PAR (Princeton Applied Research, Wellesley, MA, USA), and its radius was confirmed by means of linear voltammetry measurements using a $5 \times 10^{-3} \mathrm{~mol} \mathrm{~L}^{-1}$ aqueous solution of potassium ferricyanide also containing $0.1 \mathrm{~mol} \mathrm{~L}^{-1}$

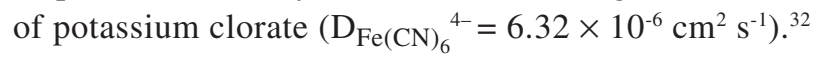
In order to improve reproducibility, the working electrode was cleaned before each measurement by immersion in acetone for $5 \mathrm{~min}$, followed by 1:1 sulfuric acid/water for 5 more min.

The electrochemical behavior of ferrocene, which was added to the MEs in the concentration of $2 \times 10^{-2} \mathrm{~mol} \mathrm{~L}^{-1}$, was characterized by cyclic voltammetry at the Pt disk UME, under a $\mathrm{N}_{2}$ stream, within the $0.0-1.1 \mathrm{~V}$ potential range, the potential being swept at 5, 10, 20, 50, 100, 200, 500, 1000 and $2000 \mathrm{mV} \mathrm{s}^{-1}$.

\section{Results and Discussion}

\section{Physical-chemical characterization of MEs}

To achieve stability of the MEs, the recommended surfactant:co-surfactant ratios lie between 1:3 and 1:4 in the case of 1-pentanol and 3-methyl-1-butanol, and between 1:4 and 1:5 for 1-hexanol. ${ }^{25}$ The results of physical-chemical characterization of the MEs are shown in Table 1. It was verified that the droplet hydrodynamic radius $\left(\mathrm{R}_{\mathrm{H}}\right)$ of the MEs prepared with 1-pentanol tended to become smaller with the increase of concentration of this co-surfactant, while for the other two tested co-surfactants, the reverse effect was observed; however, the differences were not large. Taking into account that, in comparison to the other two alcohols, 1-pentanol has the largest water solubility $(2.7,2.5$ and $0.58 \mathrm{~g} / 100 \mathrm{~g}$ water for 1-pentanol, 3-methyl-1-butanol and 1-hexanol, respectively), ${ }^{33,34}$ in the presence of 1-pentanol, a higher number of microemulsified water droplets than with the other alcohols could be formed. The number of water droplets could also increase with the 1-pentanol concentration. Since the water content remains constant, these droplets should necessarily have progressively smaller diameters. This effect is not produced when 3-methyl-1-butanol is used, probably due to the smaller separation of the hydrophilic and hydrophobic regions in its molecular structure, and maybe also to steric effects in the water/oil interface layer. This could explain the decrease of the average dimensions of the aqueous nuclei. ${ }^{35}$ Owing to the steric hindrance, and for MEs prepared with equal alcohol concentrations, the amount of 3-methyl-1butanol dissolved in the interfacial region is probably smaller than in the case of 1-pentanol. Therefore, in comparison to 1-pentanol, the 3-methyl-1-butanol concentration in the oil phase must be larger for MEs containing this alcohol. 
Table 1. Characterization of w/o MEs with different co-surfactants and surfactant:co-surfactant ratios

\begin{tabular}{|c|c|c|c|c|c|c|}
\hline Co-surfactant & [SDS]:[alcohol] ratio & $\mathrm{R}_{\mathrm{H}}{ }^{\mathrm{a}} / \mathrm{nm}$ & Refractive index & Viscosity / cP & Conductivity / $\left(\mu \mathrm{S} \mathrm{cm}^{-1}\right)$ & $\mathrm{STB}^{\mathrm{b}} /\left(\mathrm{mol} \mathrm{L}^{-1}\right)$ \\
\hline \multirow[t]{4}{*}{ 1-pentanol } & $1: 3.0$ & 4.9 & 1.440 & 13.8 & 36.2 & $6.5 \times 10^{-2}$ \\
\hline & $1: 3.5$ & 4.8 & 1.438 & 14.3 & 33.0 & $6.5 \times 10^{-2}$ \\
\hline & $1: 3.7$ & 4.1 & 1.436 & 14.0 & 31.8 & $6.5 \times 10^{-2}$ \\
\hline & $1: 4.0$ & 4.3 & 1.436 & 14.7 & 30.3 & $6.5 \times 10^{-2}$ \\
\hline \multirow[t]{3}{*}{ 3-methyl-1-butanol } & $1: 3.5$ & 3.0 & 1.435 & 14.1 & 28.8 & $5.5 \times 10^{-2}$ \\
\hline & $1: 3.7$ & 3.2 & 1.435 & 14.0 & 25.0 & $5.5 \times 10^{-2}$ \\
\hline & $1: 4.0$ & 3.2 & 1.435 & 14.1 & 21.9 & $6.0 \times 10^{-2}$ \\
\hline \multirow[t]{2}{*}{ 1-hexanol } & $1: 4.0$ & 3.6 & 1.440 & 15.4 & 10.9 & $7.0 \times 10^{-2}$ \\
\hline & $1: 5.0$ & 4.0 & 1.437 & 14.0 & 9.6 & $7.0 \times 10^{-2}$ \\
\hline
\end{tabular}

${ }^{\mathrm{a}}$ Hydrodynamic radio, established by DLS measurements; ${ }^{\mathrm{b}}$ maximum concentration not affecting the ME stability (as established by the cloud point).

MEs also showed a trend towards the reduction of the refractive index with the increase of the co-surfactant concentration. This agrees with the smaller refractive index of the alcohols with respect to that of the soybean oil (1.4093, 1.4061 and 1.4179 for 1-pentanol, 3-methyl-1butanol and 1-hexanol, respectively, but 1.475 for soybean oil). ${ }^{34,25}$

Viscosity was not expressively affected by the variation of the alcohol ratio in MEs; however, by comparing MEs with equal SDS:alcohol ratios, the MEs prepared with 1-hexanol showed the largest viscosity. This agrees with the higher viscosity of this alcohol $(4.578 \mathrm{cP})$ with respect to 1-pentanol (3.619 cP) and 3-methyl-1-butanol (3.692 cP). ${ }^{33,34}$

Then, the stability of MEs prepared with different cosurfactants, and also using distinct surfactant:co-surfactant ratios, and at increasing STB concentrations, was studied. As verified by the lack of cloudiness, MEs prepared with 1-pentanol in the 1:3.0, 1:3.5, 1:3.7 and 1:4.0 SDS: alcohol ratios, up to the maximal STB concentration tried, $6.5 \times 10^{-2} \mathrm{~mol} \mathrm{~L}^{-1}$, were stable. On the contrary, MEs prepared with low 3-methyl-1-butanol concentrations and large STB concentrations were not stable. Thus, with an 1:3 SDS:alcohol ratio, MEs were stable up to $4.5 \times 10^{-2} \mathrm{~mol} \mathrm{~L}^{-1} \mathrm{STB}$. The stability increased up to $5.5 \times 10^{-2} \mathrm{~mol} \mathrm{~L}^{-1} \mathrm{STB}$ by using $1: 3.5$ and $1: 3.7$ SDS:alcohol ratios, and up to $6.0 \times 10^{-2} \mathrm{~mol} \mathrm{~L}^{-1} \mathrm{STB}$ with a 1:4 SDS:alcohol ratio. When 1-hexanol was used as co-surfactant in MEs having 1:4 and 1:5 SDS:alcohol ratios, the maximum concentration of STB supported by the system was $7.0 \times 10^{-2} \mathrm{~mol} \mathrm{~L}^{-1}$. Thus, 1-hexanol was the co-surfactant which provided the highest stability to MEs prepared in the presence of STB.

In a previous study, it was evidenced by cloud point determination that the MEs prepared with 1-pentanol or 3-methyl-1-butanol, in the absence of added salts, are stable between 12 and $70{ }^{\circ} \mathrm{C}$, while MEs prepared with 1-hexanol are stable between 18 and $70{ }^{\circ} \mathrm{C}$. Also the stability of MEs diminished with the reduction of the cosurfactant:surfactant ratio. ${ }^{25}$

As shown in Table 1, MEs prepared with 1-pentanol were the most conductive, followed by those prepared with 3-methyl-1-butanol. MEs prepared with 1-hexanol presented the lowest values of electrical conductivity, about three times lesser than those prepared with 1-pentanol. In a previous work, it was verified that, due to the higher conductivity imparted to the MEs, the use of 1-pentanol as co-surfactant is better than 3-methyl-1-butanol. ${ }^{36} \mathrm{In}$ comparison to the use of 1-hexanol, the higher conductivity of MEs prepared with 1-pentanol is probably related with both its higher water solubility and its lower viscosity. These factors should favor percolation of the aqueous phase through the continuous oil phase, effect which could effectively contribute to the conductivity. Indeed a degree of phase percolation of this system (in the absence of soybean oil) was verified and reported elsewhere. ${ }^{31}$

Steric effects due to the molecular structure of the alcohol can be significant, especially in the case of 3-methyl-1-butanol. Thus, steric effects could explain why, under equal surfactant:co-surfactant ratios, MEs elaborated with this alcohol present the smallest $\mathrm{R}_{\mathrm{H}}$. In comparison to the other alcohols, a smaller amount of 3-methyl-1butanol seems to be present in the droplet interface. Work about how this effect affects the electrical conductivity of MEs is in progress. Owing to the highest stability and electrical conductivity of MEs prepared with 1-pentanol as co-surfactant, this alcohol was chosen in this work to perform electrochemical measurements.

\section{Electrochemical studies}

Electrochemical properties of w/o MEs may be measured using a suitable probe. Owing to its limited water solubility, diffusion-controlled electrochemical 
charge transfer and negligible adsorption on the electrode surface, ferrocene has been recommended as an adequate probe to be used in oils and MEs..$^{17,37,38}$ Ferrocene also has a relatively low molecular mass, it shows redox reversibility, electrochemical regeneration at low potential, no $\mathrm{pH}$ dependence of the redox potential, does not react with oxygen and generates stable redox forms ${ }^{39}$ In addition, the halfwave redox potential of the $\mathrm{Fc} / \mathrm{Fc}^{+}$couple is hardly influenced by the solvent, ${ }^{40}$ and the characteristics of the MEs are not affected either by the presence of ferrocene. ${ }^{41}$

A series of cyclic voltammograms obtained for a ME prepared with 1-pentanol in the presence of $2.0 \times 10^{-2} \mathrm{~mol} \mathrm{~L}^{-1}$ ferrocene at different potential sweeping rates are shown in Figure 1 (left part).

High potential sweeping rates, ${ }^{42}$ up to $10.000 \mathrm{~V} \mathrm{~s}^{-1},{ }^{43} \mathrm{can}$ be reached by using cyclic voltammetry with a Pt UME. Also, cyclic voltammetry is particularly adequate to be used in viscous media, as the MEs. Voltammograms of Figure 1 indicate that transient states of the redox system are reached in longer times in MEs than in aqueous media, which should be attributed to the larger viscosity of MEs. Taking, for instance, a planar electrode, ${ }^{20}$ the diffusion layer thickness $(\delta)$ is given by:

$\delta=(\pi D t)^{1 / 2}$

where $D$ is the diffusion coefficient of the electroactive probe and $t$, time. Using simplified models, the electrode is characterized by only one dimension, i.e. its radius $r$. Models indicate that the necessary time to reach steady state is proportional to electrode surface. ${ }^{20}$ For enough short times of potential application, any planar electrode, independently of its size, behaves as an infinitely large planar electrode in wich mass transport occurs in transient regime. During longer times, the mass transport with respect to the electrode changes to a steady regime. In this case, a ratio of $\delta / r=0.1$ ( $\delta=$ diffusion layer thickness) corresponds predominantly to a transport of mass in transient regime, whereas a ratio of $\delta / r=10$ corresponds to a steady state. For a generic hypothetical species, in function of medium viscosity, when the coefficient of diffusion diminishes from $10^{-5}$ to $10^{-7} \mathrm{~cm}^{2} \mathrm{~s}^{-1}$, the time which is necessary to reach the transient state $(\delta / r=0.1)$ in a $1 \mu \mathrm{m}$ radius UME increases from $10^{-6}$ to $10^{-4} \mathrm{~s}$.

The diffusion coefficient of ferrocene was much smaller in the $\mathrm{ME}\left(5 \times 10^{-7} \mathrm{~cm}^{2} \mathrm{~s}^{-1}\right)$ than in pure organic solvents (for instance, $1.5 \times 10^{-5} \mathrm{~cm}^{2} \mathrm{~s}^{-1}$ in THF containing $0.1 \mathrm{~mol} \mathrm{~L}^{-1}$ of tetrabutylammonium perclorate) ${ }^{44}$ It was also smaller than those of most species in aqueous solution $\left(\mathrm{ca} \cdot 10^{-6} \mathrm{~cm}^{2} \mathrm{~s}^{-1}\right)$. This made cyclic voltammetry with an UME at conventional sweeping rates to be particularly adequate for MEs. The data of Table 2 were obtained by processing the data taken from cyclic voltammograms of Figure 1.

The right part of Figure 1 shows the linear relation between $\mathrm{i}_{\mathrm{pa}}$ (peak anodic current of ferrocene) and $\mathrm{v}^{1 / 2}$ (square root of the sweeping rate) for the following sweeping rates: 5, 10, 20, 50, 100 and $200 \mathrm{mV} \mathrm{s}^{-1}$. This relationship was linear up to $100 \mathrm{mV} \mathrm{s}^{-1}$ (correlation coefficient, $r=0.996)$. The curves showed significant distortions at $500 \mathrm{mV} \mathrm{s}^{-1}$.

The linearity loss of relationship between the peak anodic current of ferrocene versus the square root of the sweeping rate, when the rate increases, indicates that a process of charge transfer under quasi-reversibility conditions occurred in the ME. Therefore, increasing the sweeping rate, the process starts to be under kinetic control. In addition, when speeds higher than $100 \mathrm{mV} \mathrm{s}^{-1}$
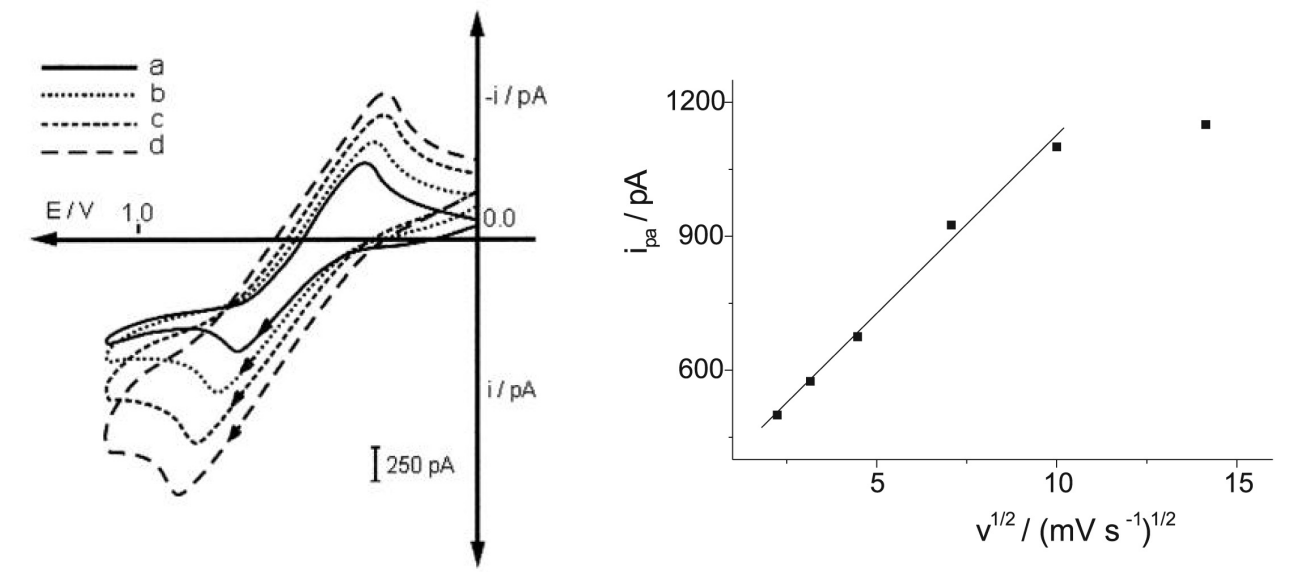

Figure 1. Voltammograms (left) and relationship between $v^{1 / 2}$ and peak anodic current (right) in a ME containing 40.0\% oil, 43.2\% 1-pentanol, 10.8\% SDS, $6.0 \%$ water and $2 \times 10^{-2} \mathrm{~mol} \mathrm{~L}^{-1}$ ferrocene. A Pt disk working UME $v s$. $\mathrm{Ag} / \mathrm{AgCl}$ reference electrode was used. Sweeping rates, v, were: 20 (a), 50 (b), 100 (c) and $200 \mathrm{mV} \mathrm{s}^{-1}$ (d). 
Table 2. Potentials of anodic $\left(\mathrm{E}_{\mathrm{pa}}\right)$ and cathodic $\left(\mathrm{E}_{\mathrm{pc}}\right)$ peaks, and currents of anodic $\left(\mathrm{i}_{\mathrm{pa}}\right)$ and cathodic $\left(\mathrm{i}_{\mathrm{pc}}\right)$ peaks obtained by cyclic voltammetry at different sweeping rates. $\mathrm{Pt}$ disk $\mathrm{UME}(1 \mu \mathrm{m}$ radius $) v s . \mathrm{Ag} / \mathrm{AgCl}$ reference electrode in a ME containing $2 \times 10^{-2} \mathrm{~mol} \mathrm{~L}^{-1}$ ferrocene

\begin{tabular}{lcccc}
\hline $\mathrm{v} /\left(\mathrm{mV} \mathrm{s}^{-1}\right)$ & $\mathrm{E}_{\mathrm{pa}} / \mathrm{V}$ & $\mathrm{E}_{\mathrm{pc}} / \mathrm{V}$ & $\mathrm{i}_{\mathrm{pa}} / \mathrm{pA}$ & $\mathrm{i}_{\mathrm{pc}} / \mathrm{pA}$ \\
\hline 5 & 0.68 & 0.43 & 500 & 575 \\
10 & 0.69 & 0.38 & 575 & 850 \\
20 & 0.72 & 0.35 & 675 & 875 \\
50 & 0.79 & 0.30 & 925 & 1050 \\
100 & 0.83 & 0.26 & 1100 & 1100 \\
200 & 0.87 & 0.25 & 1150 & 1125 \\
\hline
\end{tabular}

are considered, an accumulation of the reaction product (ferricinium ion) may occur at the electrode region. Both depletion of ferrocene and accumulation of the reaction product hinder the progress of the electrochemical reactions at the surface of the working electrode. Ferricinium ion accumulation is probably favored by the high viscosity of the ME, as well as for the preferential solubilization of this ion in the water droplets. As a consequence, ferricinium ion diffuses very slowly from the electrode surface to the bulk solution.

The reversibility condition for the transfer process of an electron of an electroactive species in the steady state can be predicted by applying the Tomes criterion $\left(\Delta \mathrm{E}=\mathrm{E}_{3 / 4}-\mathrm{E}_{1 / 4}\right){ }^{45}$ An analysis of the curve E versus $\log \left[\left(\mathrm{i}_{\lim }-\mathrm{i}\right) / \mathrm{i}\right]$ (Figure 2$)$ supplied more precise data about the reversibility of the system. ${ }^{46,47}$ For the oxidation of ferrocene in the ME, certain irreversibility of the process was evidenced. The value found for the slope of the straight-line was 0.095 , which is higher than the value that indicates reversibility for processes involving one electron $(0.059) .{ }^{48}$ Further, from diagnosis tests of the cyclic voltammetry theory, ${ }^{49,50}$ it was

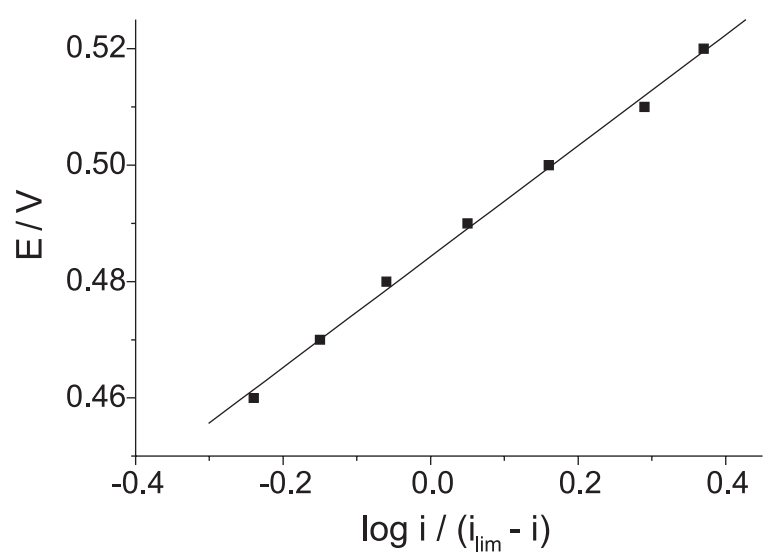

Figure 2. Relationship between $E$ and $\log i /\left(i_{\lim }-i\right)$ obtained from a linear voltammogram showing the oxidation of $2 \times 10^{-2} \mathrm{~mol} \mathrm{~L}^{-1}$ ferrocene in a ME medium $\left(\log \mathrm{i} /\left(\mathrm{i}_{\lim }-\mathrm{i}\right)=0.095 \mathrm{E}+0.484 ; \mathrm{r}=0.99838\right) ; \mathrm{v}=1 \mathrm{mV} \mathrm{s}^{-1}$ other conditions as in Figure 1. confirmed that the process approached quasi-reversibility conditions (Table 2 and Figure 1, right side).

\section{Conclusions}

In the investigated conditions, the increase of the co-surfactant content in relation to the surfactant leads to a larger thermodynamic stability of the MEs. This was important to prepare stable MEs in the presence of STB as buffer and background electrolyte. Also, the molecular structure and the solubility of the alcohol used as co-surfactant influenced expressively the electrical conductivity and the $\mathrm{R}_{\mathrm{H}}$ of the ME. Cyclic voltammetry measurements, which were carried out by using a Pt disk UME, evidenced the possibility of carrying out measurements in transient state in water/soybean oil w/o MEs, using conventional sweeping rates. This is not possible in aqueous medium with UME. Finally, ferrocene oxidation in ME has been demonstrated to proceed in quasi-reversibility conditions.

\section{Acknowledgments}

Authors are grateful to CAPES, CNPq, and Project CTQ2007-61445/BQU (Ministry of Education and Science of Spain and FEDER funds of the European Union).

\section{References}

1. Charlton, I. D.; Doherty, A. P.; J. Phys. Chem. B 2000, 104, 8061.

2. Myers, S. A.; Mackay, R. A.; Brajter-Toth, A.; Anal. Chem. 1993, 65, 3447.

3. Mackay, R. A.; Myers, S. A.; Bodalbhai, L.; Brajter-Toth, A.; Anal. Chem. 1990, 62, 1084.

4. Libster, D.; Aserin, A.; Garti, N.; J. Colloid Interface Sci. 2006, 302,322 .

5. Fua, X.; Feng, F.; Huang, B.; Int. J. Pharm. 2006, 321, 171.

6. Neto, A. A. D.; Dantas, T. N. C.; Moura, A. M. C. P.; J. Hazard. Mater. B 2004, 114, 115.

7. Fatemi, M. H.; J. Chromatogr. A 2003, 1002, 221.

8. Dave, H.; Gao, F.; Schultz, M.; Co, C.; Colloids Surf. A 2007, $296,45$.

9. Gullón, J. S.; Montiel, V. R.; Clavilier, A. J.; J. Electroanal. Chem. 2003, 554-555, 273.

10. Boso, R. L.; Bellini, M. S.; Miksík, I.; Deyl, Z.; J. Chromatogr. A 1995, 709, 11.

11. Hellweg, T.; Curr. Opin. Colloid Interface Sci. 2002, 7, 50.

12. Mc Bride, H. D.; Evans, D. G.; Anal. Chem. 1973, 45, 446.

13. Takamura, K.; Fuse, T.; Arai, K.; Kusu, F.; J. Electroanal. Chem. 1999, 468, 53. 
14. Bumajdad, A.; Eastoe, J.; J. Colloid Interface Sci. 2004, 274, 268.

15. Geraldo, M. D., Montenegro, M. I., Pletcher, D. J.; Electroanal. Chem. 1996, 418, 41.

16. Jha, B. K., Kulkarni, B. D., Vinod, M. P., Vijayamohanan, K.; Chem. Phys. Lett. 1995, 240, 442.

17 Yang, Z.; Zhao, J.; Gao, L.; Wang, T; Cao, O; Zhang, N.; Yang Z.; Anal. Lett. 2006, 39, 1801.

18. Ceballos, C.; Fernández H.; Food Res. Int. 2000, 33, 357.

19. Bard, A. J.; Faulkner, L. R.; Electrochemical Methods, Wiley \& Sons, Inc.: New York, 1980, ch. 4.

20. Stulik, K.; Amatore, C.; Holub, K.; Marecek, V.; Kutner, W.; Pure Appl. Chem. 2000, 72, 1483.

21. Yang, Z.; Zhao, J.; Lu, Y.; Du, Z.; Yang, Z.; Chem. Phys. 2004, $307,71$.

22. Schuette, S. A.; McCreery, R. L.; J. Electroanal. Chem. 1985, 191, 329.

23. Del Pozo, J. A.; Costa-Garcia, A.; Blanco, P. T.; Anal. Chim. Acta 1994, 289, 169.

24. Howell, J. O.; Gonçalves, J. M.; Amatore, C.; Klasinc, L.; Wightman, R. M.; Kochi, J. K.; J. Am. Chem. Soc. 1984, 106, 3968.

25. Mendonça, C. R. B.; Bica, C. I. D.; Piatnicki, C. M. S.; J. Braz. Chem. Soc. 2003, 14, 628.

26. Tomkins, R. P. T.; Popovych, O.; Nonaqueous Solution Chemistry, John Wiley \& Sons: New York, 1979.

27. Beckmann, A.; Schneider, A.; Gründler, P.; Electrochem. Commun. 1999, 1, 46.

28. Pohjakallio, M.; Sundholm, G.; Talonen, P.; J. Electroanal. Chem. 1996, 401, 191.

29. Viswanathan, S.; Ho. J.; Biosens. Bioelectron. 2007, 22 , 1147.

30. Provencher, S. W.; Makromol. Chem. 1979, 180, 201.

31. Mendonça, C. R. B.; Bica, C. I. D.; Piatnicki, C. M. S.; SimóAlfonso, E. F.; Ramis-Ramos, G.; Electrophoresis 2005, 26, 858.

32. Kawiak, J.; Kulesza, P. J.; Galus, Z. J.; Electroanal. Chem. 1987, 226, 305.

33. Budavari, S., ed.; The Merck Index: An Encyclopedia of Chemical, Drugs, and Biological, $12^{\text {th }}$ ed., Merck \& CO Inc.: New Jersey, 1996.
34. Lide, D. R., ed.; Handbook of Chemistry and Physics, $78^{\text {th }}$ ed., CRC Press: Boca Raton, 1997-1998.

35. Cazabat, A. M.; Langevin, D.; J. Chem. Phys. 1981, 74, 3148.

36. Mendonça, C. R. B.; Bica, C. I. D.; Piatnicki, C. M. S.; Abstracts of the 11th International Conference on Surface and Colloid Science, Foz do Iguaçu, Brazil, 2003, p. 285.

37. Mackay, R. A.; Adv. Colloid Interface Sci. 1981, 15, 131.

38. Georges, J., Berthod, A.; J. Electroanal. Chem. 1984, 175, 143.

39. Fernández, L: Carrero, H.; Electrochim. Acta 2005, 50, 1233.

40. Matsumiya, M.; Terazono, M.; Tokuraku, K.; Electrochim. Acta 2006, 51, 1178.

41. Santhanalakshmi, J., Anadhi, K.; J. Colloid Interface Sci. 1995, 176, 226.

42. Amatore, C.; Maisonhaute, E.; Simonneau, G.; J. Electroanal. Chem. 2000, 486, 141.

43. Amatore, C. In Microelectrodes; Fleischmann, M.; Pons, S.; Rolison, D. R.; Schmidt, P., eds.; Ultramicroelectrode, Datatech Systems, Inc.: Morgantown, NC, US, 1987.

44. Cassoux, P.; Dartiguepeyron, R.; Fabre, P. L.; Montazon, D.; Electrochim. Acta 1985, 30, 1485.

45. Charlot, G.; Badoz-Lambling, J.; Trémillon, B.; Les Réactions Électrochimiques, Masson: Paris, 1959.

46. Santhanalakshmi, J.; Anadhi, K.; J. Colloid Interface Sci. 1995, 176, 226.

47. Daniele, S.; Baldo, M.A.; Bragato, C.; Electrochem. Comm. 1999, 1,37 .

48. Jiang, J. J.; Wu, B.; Cha, C.; Electrochim. Acta 1997, 42, 1421.

49. Greef, R.; Peat, R.; Peter, L. M.; Pletcher, D.; Robinson, J.; Instrumental Methods in Electrochemistry, John Wiley \& Sons: New York, 1985.

50. Ohsawa, Y.; Aoyagui, S.; J. Electroanal. Chem. 1982, 136, 353.

Received: September 29, 2007 Web Release Date: May 5, 2008 